\title{
Joanna Orzechowska-Waclawska*
}

\section{REWITALIZACJA PO BASKIJSKU. KULTUROWY KOD ,EFEKTU GUGGENHEIMA"}

\begin{abstract}
Abstrakt. Niniejszy artykuł poświęcony jest tzw. „,efektowi Bilbao”. Zasadniczą osią pracy jest analiza szczególnej relacji pomiędzy zastosowaną w Bilbao strategią rewitalizacji miasta, z ikoniczną dla całego przedsięwzięcia budowlą, jaką było Muzeum Guggenheima, a kulturą Basków, a więc ich sposobem życia i wartościami wspólnotowymi. Punktem wyjścia dla zawartych tu rozważań jest pojęcie „rewitalizacji przez kulturę”, które rozumiane bywa dwojako. Po pierwsze (najczęściej), interpretuje się je jako całokształt działań polegających na wykorzystaniu w projektach rewitalizacji miast obiektów lub instytucji kultury. Według drugiej interpretacji, termin ten opisuje proces przywracania miasta do życia odbywający się dzięki aktywności (najlepiej lokalnych) artystów. W obydwu jednak przypadkach, istota kultury zostaje istotnie wypaczona, ponieważ zarówno w pierwszym, jak i drugim znaczeniu, zakres jej rozumienia zostaje spłycony, a sama kultura potraktowana w istocie jako synonim ,sztuki”.

Wychodząc od definicji Floriana Znanieckiego, który kulturę rozumie nie tylko w kategoriach materialnych, lecz także jako wszystko to, co zamyka się w ,niematerialnych wytworach działalności ludzkiej”, „kulturowość” bilbaońskiej rewitalizacji przedstawiona jest w niniejszej pracy nie przez pryzmat Muzeum Guggenheima jak przykładu instytucji kultury, lecz poprzez odniesienie się do zastosowanej w Bilbao strategii rewitalizacyjnej i jej oparcia w społeczności lokalnej. Artykuł zawiera więc analizę relacji pomiędzy Muzeum Guggenheima w Bilbao a baskijską filozofią polityczna, szeroko pojmowanymi baskijskim wartościami ekonomicznymi, jak również Basków wizją samych siebie.
\end{abstract}

Słowa kluczowe: Muzeum Guggenheima, Bilbao, rewitalizacja, Kraj Basków.

19 października 1997 roku Muzeum Guggenheima w Bilbao otwarło swoje drzwi dla zwiedzających. Tłumy ustawiły się w kolejce. Pierwszego dnia ponad cztery i pół tysiąca osób oglądnęło ekspozycję muzeum (S a n ta maría 2007: 116). W ciagu niecałych trzech miesięcy (do końca 1997 roku) bilbaońskie muzeum odwiedziło prawie 260 tys. osób, a do końca 1998 roku - przeszło półtora miliona. Średnio, każdego roku muzeum przyjmuje około miliona ludzi ${ }^{1}$, co plasuje je w gronie pierwszych 70 najczęściej odwiedzanych muzeów świata² 2 .

\footnotetext{
*Uniwersytet Jagielloński, Instytut Europeistyki, joanna.orzechowska-waclawska@uj.edu.pl

${ }^{1}$ Guggenheim Muzeum, Bilbao, Notas de prensa, lata 2000-2014.

2 The Art. Newspaper. International Edition, dane za 2013 rok.
} 
Ponad połowę zwiedzających stanowią obcokrajowcy, w tym przede wszystkim Francuzi, Brytyjczycy, Niemcy, Amerykanie i Włosi ${ }^{3}$. Nie jest to zaskakujące, jeśli weźmie się pod uwagę niezwykły międzynarodowy rozgłos medialny, jaki od samego początku towarzyszył inwestycji. Według szacunków Gerardo del Cerro Santamaríi, z około ośmiu i pół tysiąca (!) artykułów prasowych, które ukazały się w ciagu pierwszych dwóch lat istnienia muzeum, ponad połowę wydano właśnie poza granicami Hiszpanii (t a m ż e: 102). Wielkie tytuły, takie jak: „The New York Times”, „The Time”, „The Economist”, „The Washington Post” i wiele innych pisało o niezwykłej budowli powstającej właśnie w Bilbao. Guggenheim Gehry'ego - jak pisał Robert Hughes na łamach „The Time” - „uderzył Bilbao z siła architektonicznego meteorytu" (H u gh e s 1997). Niemal z dnia na dzień obiekt stał się światową sensacją, umieszczając Bilbao na mapie najważniejszych destynacji turystyki kulturowej. Muzeum powszechnie przedstawiano jako wyjątkowe, ekscytujące, przełamujące bariery. Uznano je za jedną z najważniejszych budowli ubiegłego stulecia, a według „The Time” - za „pierwszy wielki budynek XXI wieku, który ukazał się o kilka lat za wcześnie"4. Herbert Muschamp, znany i niezwykle wpływowy krytyk architektury z „The New York Times”, mówił wprost o cudzie, który za sprawą Muzeum Guggenheima w Bilbao dokonywał się w sztuce. „«Czy byłeś w Bilbao?» - jak pisał Muschamp - w kręgach architektury to pytanie stało się już niemal sloganem. Czy widziałeś światło? Czy widziałeś przyszłość?" (Muschamp 1997). Nie można było uznawać się za konesera sztuki współczesnej i miłośnika architektury i nie pojechać do Bilbao, by zobaczyć dzieło Franka Gehry'ego. Ale Muzeum Guggenheima przyciagało do miasta nie tylko wyrafinowanych znawców sztuki, lecz także rzesze turystów. Ten nowy - w bilbaońskim doświadczeniu - „konsument kultury” przyjeżdżał do Bilbao nie tylko po to, by obcować ze sztuką (czyli w praktyce dokonać jej konsumpcji: pójść do muzeum, zwiedzić sklep muzealny, kupić pamiątki, zjeść obiad w restauracji muzeum), lecz także, by zaspokoić swoją potrzebę b y c i a w miejscu, w którym nowoczesny, podążający za trendami człowiek powinien bywać. Chęci zobaczenia osławionego projektu architektonicznego (dalece bardziej niż potrzebie zobaczenia ekspozycji!) towarzyszyła także ciekawość dotycząca samego regionu, w którym muzeum usytuowano, a tę skutecznie podsycała narracja prasowa. Oto bowiem bardzo prestiżowa amerykańska fundacja kultury decyduje się, by europejską filię swojego muzeum otworzyć w nieznanym szerszej opinii publicznej mieście, znajdującym się na północy Półwyspu Iberyjskiego, o którym wiadomo właściwie tylko tyle, że jest usytuowane w Kraju Basków - miejscu uznawanym za niebezpieczne, powszechnie kojarzonym z działalnością terrorystycznej grupy ETA. Region ten musiał być też niezwykle zamożny - a to dodatkowo wzmacniało zainteresowanie odbiorców - bo o tym, że na budowę samego

3 Guggenheim Muzeum, Bilbao, Notas de prensa, lata 2000-2014.

${ }^{4}$ The best design of 1997, "Time", 29 December 1997. 
budynku Baskowie zdecydowali się wydać aż 100 milionów dolarów, nie mówiąc już o pozostałych kosztach związanych z działalnością muzeum i franczyzą, pisały niemal wszystkie tytuły zajmujące się tą sprawą.

Muzeum Guggenheima w dużej mierze właśnie dzięki prasie - na co zwraca uwagę Ari Seligmann z Uniwersytetu w Kalifornii (S e li g m a n n 2008) - stało się magnesem, który ściagnął na miasto uwagę międzynarodową i przyciągnął do niego turystów z całego świata. Taki zresztą był też główny zamysł liderów baskijskich i pomysłodawców bilbaońskiej rewitalizacji. Chodziło o to, by za sprawą wielkiej ikonicznej budowli zmienić negatywny wizerunek Basków poza granicami kraju i przyciagnąć do miasta (i całego regionu) biznesmenów o aspiracjach kulturowych i turystów o zasobnych portfelach (M a c Cla n c y 2007: 164). To, jak zły był obraz Kraju Basków na świecie, świetnie ilustrują badania Iñaki'ego Zabalety. Przestudiowawszy artykuły prasowe poświęcone Baskom, opublikowane w „The New York Times” w latach 1950-1996, Zabaleta zauważył, że zasadnicza większość poświęcona była kwestii konfliktu (niemal 94\% z 674 artykułów wydanych w tym okresie, z czego 65,5\% dotyczyło kwestii terroryzmu w Kraju Basków) (Zabaleta 1999). Otwarcie Muzeum Guggenheima z perspektywy władz regionu było zatem strategią marketingową, mającą zmienić sposób postrzegania Basków na świecie.

Zarówno dla strony baskijskiej, jak też dla Fundacji cała inwestycja obarczona była znacznym ryzykiem. Tomas Krenz, dyrektor Fundacji, ryzykował nie tylko swoją reputacja, lecz także wizerunkiem instytucji, którą reprezentował. Niejednokrotnie musiał więc tłumaczyć się z podjętej decyzji i wiele razy - także ze względów bezpieczeństwa - odradzano mu wyjazd do Kraju Basków. Dla Basków z kolei całe przedsięwzięcie wiązało się przede wszystkim z olbrzymimi kosztami, i to nie tylko finansowymi, lecz także społecznymi i politycznymi. Decyzja o porozumieniu w sprawie budowy muzeum budziła szereg kontrowersji i opór ze strony lokalnego świata artystycznego ${ }^{5}$. Była także potencjalnie niebezpieczna z uwagi na groźby atakiem terrorystycznym ze strony ETA.

Pierwsze efekty budowy Muzeum Guggenheima dały się zauważyć już kilka miesięcy po jego otwarciu. Muzeum okrzyknięto ikoną współczesnej architektury, która niemal natychmiast przeistoczyła się w wizytówkę Bilbao, a zarazem świetną markę promującą miasto i cały region na zewnątrz. W powszechnym odbiorze, jak słusznie zauważa Joan Ockman, muzeum zaczęło funkcjonować niemal jako „synonim miasta” (O c k m a n, za J o h n s o n 2009: 124), przyczyniając się do radykalnej zmiany sposobu mówienia i myślenia o nim. Bilbao zaczęto opisywać i postrzegać tak jak samego Guggenheima: jako nowoczesne, innowacyjne i otwarte na świat.

${ }^{5}$ Jorge Oteiza, osobowość baskijskiego świata artystycznego, odmówił udostępnienia swoich prac Muzeum Guggenheima. W liście do prezydenta Kraju Basków opisywał projekt jako „wart Disneya, całkowicie antybaskijski, mogący spowodować wielką szkodę i sparaliżować całą działalność kulturalną, jaka mogłaby się wytworzyć w naszym kraju” (za: S a n t a m a ría 2007: 112). 
Bardzo dobrą ilustracją pokazującą skalę zainteresowania, jakie wygenerowało muzeum, są statystyki ukazujące zmiany ruchu turystycznego w regionie, w tym przede wszystkim te, które dotyczą liczby osób korzystających w Bilbao $z$ usług hotelarskich. O ile przed otwarciem Muzeum Guggenheima średnio w hotelach nocowało około 250 tys. osób rocznie (średnia z lat 1992-1996), bez znaczących fluktuacji pomiędzy latami, o tyle rok 1997 (otwarcie muzeum) stanowi wyraźną cezurę - liczba osób meldujących się w bilbaońskich hotelach w ciagu jednego roku wzrosła o ponad połowę (z 288884 w 1997 roku do 434686 w roku 1998). W największym stopniu zwiększył się odsetek obcokrajowców, którzy począwszy od 1997 roku zaczęli niemal masowo ściagać do Bilbao. Liczba cudzoziemców korzystających z usług hotelarskich w mieście w 1998 roku była ponad dwukrotnie wyższa niż w roku poprzednim (61 173 w 1997 r., 126953 w 1998 r.) i niemal pięciokrotnie wyższa w roku 2013 (296 853) niż na początku okresu. Nie ma wątpliwości, że za te zmiany ruchu turystycznego odpowiada Muzeum Guggenheima. $Z$ taką konkluzją korespondują też wyniki badań prowadzonych wśród zwiedzających, z których wynika, że główną przyczyną ich wizyty w Bilbao była chęć zobaczenia muzeum ${ }^{6}$.

Przyjazdy turystów znacząco wpłynęły na rozwój baskijskiego sektora usług. Okolice Muzeum Guggenheima, blisko Plaza Moyua, zamieniały się powoli w dzielnicę pełną eleganckich sklepów. Bilbao dzięki zaplanowanym działaniom rewitalizacyjnym, ale także samoistnie - w odpowiedzi na wzrost popytu wywołany turystyka, przemieniało się stopniowo w nowoczesne centrum kulturalno-finansowe. Korzystając z bogatej oferty turystyczno-usługowej (bary, restauracje, sklepy, hotele, kina, teatry, muzea), turyści pozostawiali w mieście znaczne sumy pieniędzy. Według estymacji muzeum, pośrednie (wydatki turystów w mieście), jak i bezpośrednie (wydatki zwiedzających w muzeum) wpływy z jego działalności zwiększają PKB Kraju Basków o około 2380 mld euro rocznie, co daje roczną kontrybucję do budżetu baskijskiego rzędu 25-30 mln euro (O r ze c how ska-Wacław ska 2014: 223).

Wizerunkowa zmiana miasta, która dokonała się dzięki muzeum, i towarzyszące jej ożywienie gospodarcze ${ }^{7}$ (wzrost turystyki i wzrost dochodów w regionie) spowodowały, że bilbaońską rewitalizację szybko okrzyknięto mianem sukcesu. Stawiano jąjako punkt odniesienia dla projektowania i egzekucji działań rewitali-

${ }^{6}$ Guggenheim Muzeum, Bilbao, Study of the Economic Impact of the Activities of the Guggenheim Museum Bilbao - Estimation for 2011, 30 December 2011.

${ }^{7}$ Kwestia dotycząca tego, czy i na ile Muzeum Guggenheima spełniło pokładane w nim nadzieje na rozwój ekonomiczny regionu, budzi wciąż sporo kontrowersji. Z jednej strony zwraca się uwagę na wzrost turystyki oraz wpływy do budżetu miasta będące konsekwencją jego otwarcia (P la za 2006, 2008), z drugiej zaś, pojawiają się głosy krytyczne, sugerujące, że Muzeum Guggenheima nie przyczyniło się do realnej ekonomicznej rewitalizacji regionu (G ó m e z, G o n zále z 2001), a nawet stało się źródłem negatywnych przemian socjoekonomicznych, czego przejawem jest wzrost cen nieruchomości w Bilbao (Vi c ari o, Martín e z 2003). 
zacyjnych w ośrodkach poprzemysłowych. $Z$ dnia na dzień zaczęto mówić o tzw. „efekcie Bilbao”. Powszechnie wyrażano nadzieje na jego powtórzenie w innych - dziś podupadłych, a kiedyś dobrze prosperujących - centrach przemysłu.

\section{Budowanie narracji: „efekt Bilbao” jako „efekt Guggenheima”}

Choć samo pojęcie „efektu Bilbao” było kreacją medialną, bardzo szybko przedostało się do codziennego języka i z powodzeniem zaczęto je stosować także w piśmiennictwie naukowym. Ten w istocie niezwykle pojemny termin wyrażać miał to, co powszechnie - i niestety nazbyt pobieżnie - uznaje się za istotę procesów rewitalizacyjnych w Bilbao, a więc przekonanie o tym, że wielkoskalowa spektakularna inwestycja, najlepiej w obiekt kultury, w którym wykorzystany zostanie innowacyjny pomysł architektoniczny, będzie miała szansę - tak jak to miało miejsce w Bilbao - wzbudzić ogromną falę zainteresowania, przyciagnąć do miasta rzesze turystów, a dzięki temu wpłynąć pozytywnie na sytuację gospodarczą miasta i zmienić jego obraz na świecie. Ponieważ centralnym punktem i flagową inwestycją bilbaońskiej rewitalizacji było Muzeum Guggenheima, często w tym samym znaczeniu używa się pojęcia „efekt Guggenheima”, który jeszcze dobitniej buduje przekonanie o prostym związku pomiędzy budową muzeum i przeobrażeniami ekonomicznymi i wizerunkowymi w mieście.

Mimo iż „efekt Bilbao” miał wyrażać kwintesencję bilbaońskiego modelu rewitalizacji, wraz z rosnącą popularnością termin ten szybko oderwał się od kontekstu (miasta, regionu, społeczności), w którym był zakotwiczony i który miał definiować, zamieniając się, jak trafnie zauważa Seligmann, „w eufemizm opisujący pożądane skutki rewitalizacji miast na całym świecie" (S e li g m a n n 2008: 38-39).

O przebiegu bilbaońskiej rewitalizacji i jej skutkach społecznych, ekonomicznych i wizerunkowych pisałam szczegółowo na łamach „Politeji” (2014, $\mathrm{nr} 27)$. W tym miejscu nie będę powtarzać zawartych tam tez, przytoczę jednak trzy zasadnicze konkluzje płynące z tej pracy, bowiem rozważania zawarte w niniejszym artykule stanowią naturalną kontynuację i konieczne uzupełnienie opisywanych przeze mnie wcześniej zjawisk. Po pierwsze, jak podkreślałam, budowa Muzeum Guggenheima w Bilbao była jedynie częścią - jakkolwiek niezwykle ważną - szerszej strategii rewitalizacyjnej prowadzonej w mieście. Jej całościowy i wieloaspektowy charakter przejawiał się zarówno: 1) w szerokim horyzoncie czasowym i przestrzennym, $w$ jakim zaplanowano działania rewitalizacyjne (prowadzenie projektów rewitalizacyjnych w różnych dzielnicach i regionach miasta, nie tylko na obszarze samej jego części nabrzeżnej, Abandoibarry, gdzie usytuowane jest muzeum), jak i 2) w różnorodności inwestycji (nie były to jedynie wielkoskalowe projekty w obiekty kulturowe czy centra finansowe, lecz także projekty zorientowane na rozbudowę infrastruktury miasta i jego sieci transportowej). Choć Muzeum Guggenheima miało stanowić flagową inwestycję całego 
procesu, powodzenie tego przedsięwzięcia zależało w rzeczywistości od wielu równocześnie prowadzonych w Bilbao inicjatyw rewitalizacyjnych. Po drugie, zwracałam szczególną uwagę na instytucje partnerstwa publiczno-prywatnego, w tym dwie kluczowe organizacje, które odpowiedzialne były za planowanie oraz koordynowanie całego procesu, tj. Bilbao Metropoli 30 i Bilbao Ria 2000. Z uwagi na rolę, jaką odegrały one w całym przedsięwzięciu i ich bardzo specyficzny charakter (mam na myśli przede wszystkim Bilbao Ria 2000), do inicjatyw tych powróce jeszcze w tej pracy. Po trzecie, podkreślałam znaczenie kontekstu, bez którego nie sposób właściwie oddać zmiany, która zaszła w ciagu ostatnich dwudziestu lat w Bilbao. Koncentrowałam się w szczególności na opisie historii miasta, podkreślając jego znaczenie jako baskijskiego miasta portowego i ważnego ośrodka przemysłowo-handlowego.

Tematem, który nie został zaadresowany w poprzedniej pracy, a który ma fundamentalne znaczenie dla zrozumienia istoty „efektu Bilbao”, jest jego szczególny kontekst kulturowy. To właśnie on stanowi przedmiot zainteresowania niniejszego artykułu. Zajmować mnie będzie przede wszystkim problem roli i znaczenia kultury miejsca (regionu) ikultury społeczności zamieszkującej to miejsce, w kształtowaniu procesów rewitalizacyjnych. Zasadniczym celem pracy jest pokazanie, że sukces bilbaońskiej rewitalizacji, a więc opisywane wyżej ekonomiczne i wizerunkowe konsekwencje budowy Muzeum Guggenheima, które nazywa się mianem ,efektu Bilbao”, są przede wszystkim wynikiem właściwego zakotwiczenia strategii rewitalizacyjnej w baskijskim kodzie kulturowym.

\section{Rewitalizacja przez kulturę}

Nikt nie zaprzeczy dziś twierdzeniu, że kultura ogrywa ważną rolę przy planowaniu i egzekucji projektów rewitalizacyjnych we współczesnych miastach. Rozumiana zarówno jako system wartości i podzielanych znaczeń ( $\mathrm{McEwan}$ 2005), jak również symbole, historie, praktyki i rytuały, wykorzystywane przez ludzi do tworzenia różnorakich „strategii działania” (S widler 1986), kultura wpływa na sposób postrzegania rzeczywistości, determinuje, co w danej społeczności uznawane jest za ważne i cenione, a więc co należy chronić i utrwalać. Szeroko rozumiana kultura stanowi jedno ze źródeł tworzenia kapitału społecznego i jako taka zawarta jest we wszelkich przejawach aktywności człowieka, także tych, które realizują się w przestrzeni miejskiej.

Mimo oczywistości tych stwierdzeń i powszechności przekonania, że kultura jest immanentnym komponentem społeczeństwa, a zatem powinna być uwzględniana na każdym etapie działań rewitalizacyjnych, w praktyce jej rolę w procesie przywracania przestrzeni miejskiej do życia rozumie się zwykle bardzo wąsko. Popularną dziś koncepcję „rewitalizacji przez kulturę” sprowadza się zwykle do opisu takich działań, które polegają na wykorzystaniu w projektach rewitalizacji 
miast obiektów lub instytucji kultury, a więc najczęściej muzeów, a także filharmonii, teatrów czy oper. Tego typu podejście, które idealnie wpisuje się w fenomen, który Lisanne Gibson i Deborah Stevenson nieco ironicznie opisują mianem filozofii „dodaj kulturę i zamieszaj” (G i b s o n, S te v e n s o n 2004: 1), jest częstą charakterystyką współcześnie prowadzonych projektów rewitalizacyjnych.

Punktem wyjścia takich polityk jest zwykle wyobrażenie pewnego ideału „miasta kreatywnego”, a więc przekonanie o tym, że współczesne miasto, aby móc dynamicznie się rozwijać, powinno stać się ośrodkiem „kreatywnym”, tj. takim, który - jak trafnie (i celowo w nieco przejaskrawiony sposób) podsumowuje Allen J. Scott - skupia utalentowanych i wykwalifikowanych pracowników zatrudnionych w nowych, w domyśle: innowacyjnych przemysłach, gdzie wysoki standard życia idzie w parze z dbałością o środowisko naturalne, które zapewnia swobodę samorealizacji i ekspresji, oferując mieszkańcom szereg atrakcji i rozrywek, gdzie bujnie rozwija się życie nocne, a nieustannie organizowane festiwale i spektakle są dowodem dynamizmu jego środowiska twórczego, architektura miasta zaś z jej spektakularnymi budowlami staje się ostatecznym świadectwem jego światowości, otwartości i unikatowości (S c ott 2014: 566). Podstawowym atrybutem tak rozumianego miasta nie jest już jego potencjał produkcyjny, zdolności wytwórcze i sieć kontaktów handlowych, jak w typowym fordowskim mieście industrialnym, lecz szeroko rozumiana at r a k c yjn ość. Tę, z kolei, na poziomie decydentów politycznych rozumie się często jako zdolność miasta do przyciągnięcia uwagi międzynarodowej, stawiając ją wyżej ponad wygodę i jakość życia jego (aktualnych) mieszkańców. Ostateczną miarą sukcesu miasta - zgodnie z taką logiką - staje się liczba sprowadzonych do niego turystów, kapitału i „klasy kreatywnej”. To wyraźne przeniesienie akcentów - z „obiektywnych”, namacalnych determinant miasta, wynikających dawniej przede wszystkim z jego usytuowania geograficznego, bliskości zasobów naturalnych, liczby hut, fabryk i innych zakładów przemysłowych, jakości procesu produkcyjnego, dostępności siły roboczej i kosztów pracy - w kierunku aspektów bardziej „subiektywnych”, bo odnoszących się do sfery postrzegania ludzkiego, powoduje, że wiele dzisiejszych polityk rewitalizacyjnych nastawionych jest w pierwszej kolejności na realizację takich działań, które mogą bezpośrednio przełożyć się na kwestie wizerunkowe. Ostatecznym ich celem jest więc często „unowocześnienie” i uatrakcyjnienie obrazu miasta w oczach szeroko rozumianej opinii publicznej. Kultura świetnie się do tego nadaje, ponieważ dostarcza doświadczeń nadających się do sprzedaży i konsumpcji, przyciagając do miasta „klasę kreatywną” i turystów kulturowych (A s h w or th, Ka va rat zi i 2014), i w tym znaczeniu staje się szczególnym rodzajem „zasobu” ekonomicznego, który może przynieść kwantyfikowane skutki gospodarcze.

Kavaratzis i Ashworth (2015) w swojej analizie dotyczącej wykorzystania kultury do kreacji wizerunku miasta wyróżniają trzy zasadnicze formy, które takie działania przybierają. Są nimi: 1) organizacja wielkich wydarzeń kul- 
turalnych (np. festiwali) jako mechanizm promocji miasta jako ośrodka kultury, 2) budowanie asocjacji pomiędzy miejscem a ważną postacią świata artystycznego lub literackiego w nadziei, że cechy wyróżniające twórczość tego artysty zostaną ,rozciagnięte" na miasto, oraz 3) tworzenie ikonicznych budowli mających świadczyć o twórczym i wyjątkowym charakterze ośrodka (ta m że). Choć każda $\mathrm{z}$ tych strategii odwołuje się bezpośrednio do kultury, jej rozumienie jest za każdym razem w istocie niezwykle powierzchowne. W pewien sposób kultura - jak sugeruja - zostaje ,uprowadzona” przez polityki wizerunkowe, pojawia się bowiem rozdźwięk pomiędzy tym, co stanowi kwintesencję kultury lokalnej (i co teoretycznie powinno być zintegrowane w wizerunku miasta, a nie jest), a tym, co wyraża konkretna marka miejsca.

Muzeum Guggehneima w Bilbao, wpisujące się w ostatni z tu wymienionych sposobów budowania wizerunku miasta - zgodnie z narracją tych autorów - stanowić ma dobrą ilustrację takiego właśnie „uprowadzenia” kultury, a to dlatego, że zmiana obrazu miasta i poprawa jego sytuacji ekonomicznej miały dokonać się za ,sprawą jednej budowli, która mieszcząc w sobie wytwory kultury, sama jawiła się jako kulturowa" (t a m ż e: 161). Zasadniczym punktem przedstawionej przez obydwu autorów krytyki jest problem braku kohezji między globalną marka, jaką stało się Muzeum Guggenheima, a lokalną aktywnością kulturalną. „Zakres, w jakim [muzeum] stworzyło bodźce dla rozwoju lokalnej twórczości artystycznej, był - jak sugerują - wątpliwy" (t a m że). O ile ogólna konstatacja płynąca z ich analizy dotyczącej „uprowadzenia” kultury przez różne formy i strategie marketingowe i pojawiającego się w związku z tym rozdźwięku pomiędzy marką miasta a lokalnością, jest niezwykle przekonująca, o tyle konkluzje autorów dotyczące Muzeum Guggenheima wymagają dodatkowego komentarza.

\section{Kulturowy kod Muzeum Guggenheima}

U Kevartzisa i Ashwortha pojawiają się dwa typowe dla naukowego i nie-naukowego dyskursu poświęconego „efektowi Bilbao” uproszczenia. Pierwszym jest uznanie muzeum nie tylko za główny obiekt, ale też i główną tre ś ć bilbaońskiej rewitalizacji. Zamiast więc opisywać „efekt Bilbao” poprzez odwołanie się zarówno do strategi i rewitalizacyjnej (czyli: Jak rewitalizować? Kto ma odpowiadać za proces? Kogo uwzględniać (kogo pomijać)? Gdzie prowadzić działania rewitalizacyjne? Jak rozstrzygać kwestie problemowe? Kto ma je rozstrzygać?), jak i konkretnego s p o s o bu rewitalizacji (czyli: Co zbudować? Co zorganizować?), zwykle mowa jedynie o tym ostatnim. W rezultacie cała ocena rewitalizacji Bilbao dokonywana jest jedynie przez pryzmat Muzeum Guggenheima. Prowadzi to do całkowitego zbanalizowania „efektu Bilbao”, budując - niejednokrotnie wbrew intencji samych autorów - wyobrażanie, że do jego powtórzenia wystarczy jedna wielkoskalowa inwestycja w obiekt kultury, a je- 
dynym potencjalnym wyzwaniem, które mogłoby utrudnić osiagnięcie zamierzonego celu, jest to, czy budowla będzie na tyle spektakularna i innowacyjna, że spodoba się krytykom architektury i dziennikarzom, a dzięki nim także opinii publicznej.

Drugie uproszczenie wynika poniekąd z pierwszego. Jest nim mianowicie założenie, że wykorzystanie kultury w procesie rewitalizacji polega albo na inwestycji w obiekt kultury, albo też na organizacji jakiegoś kulturalnego wydarzenia. Jeśli projekt ten nawiąże, wywiedzie się lub choćby w efekcie zaktywizuje lokalnych twórców, wówczas zostanie powszechnie uznany za w pełn i „kulturowy”. Taki właśnie tok rozumowania pojawia się we wspomnianej analizie Kevartzisa i Ashwortha. Krytykując politykę miejską, której kulturowy charakter ma być reprezentowany przez wzniesienie odpowiedniej budowli kulturowej (muzeum, filharmonii, itd.) lub zorganizowanie wydarzenia kulturalnego, autorzy sugeruja, że prawdziwa polityka kulturalna winna w pierwszej kolejności odwoływać się do lokalnych artystów. Podstawowym błędem obydwu tych narracji, z których pierwszą proponuję nazwać „odgórną” - jako strategię często wspieraną i inicjowaną przez władze (samorządowe, regionalne), drugą zaś „oddolną” - bo wypływająca z inicjatyw lokalnych, jest pojawiające się w obu sprowadzenie koncepcji kultury do tego, co wyraża się pod pojęciem sztuki. W dyskursie dotyczącym wykorzystania kultury do prowadzenia działań rewitalizacyjnych, a Bilbao jest tego najlepszym przykładem, zasadnicza uwaga skoncentrowana jest zwykle na wytworach (dziełach) artystycznych lub - rzadziej - twórczości (procesie) artystycznej, i to one stają się tym, co odpowiadać ma za „kulturowość” rewitalizacji. To, co w takich analizach nie jest należycie brane pod uwagę, to fakt, że kultura to nie tylko dzieła sztuki, budowle i festiwale, i nie tworzą jej jedynie artyści i miejscowa bohema. Kultura to także sposób życia i funkcjonowania danej społeczności oraz wyznawany przez nią s y stem wartości. To one mieszczą się w tym komponencie kultury, który Florian Znaniecki bardzo trafnie nazywał „niematerialnymi wytworami działalności ludzkiej”.

Mając powyższe na uwadze, proponuję, aby „kulturowość” bilbaońskiej rewitalizacji badać nie przez pryzmat Muzeum Guggenheima jako instytucji kultury - jak to zwykle się zakłada - lecz poprzez odniesienie się do zastosowanej tam strategii i jej oparcia w społeczności lokalnej. Chodzi więc o spojrzenie na polityki miejskie z punktu widzenia: 1) specyficznej filozofii politycznej Basków, 2) ich szeroko pojmowanych wartości ekonomicznych, jak i pewnej 3) wizji siebie samych. Ten szczególny kontekst kulturowy, który odnosi się tak do miejsca (Bilbao i szerzej - Kraj Basków), jak i społeczności (Baskowie), pozwala zrozumieć, dlaczego „efekt Bilbao” nastapił i dlaczego Muzeum Guggenheima, zaprojektowane przez kanadyjsko-amerykańskiego architekta i znajdujące się w rękach amerykańskiej fundacji kultury, zaczyna - na poziomie identyfikacji grupowej-stawać się ważnym, pozytywnym punktem odniesienia dla kształtowania współczesnej tożsamości bilbaońskiej. 


\section{Muzeum Guggenheima jako pomnik niezależności}

Wiele prawdy jest w stwierdzeniu, że sztandarowe budowle są czymś więcej aniżeli tylko budynkami mającymi pomieścić to, co stanowi ich oficjalną funkcję. Poprzez samą fizyczną obecność w przestrzeni publicznej stają się one swoistymi pomnikami władzy i rządów, które je wznoszą i w tym sensie są szczególnego rodzaju „okrętami flagowymi polityk i idei”, które za nimi stoją (K a v a ratz is, A s hw o r th 2015: 160). W przypadku Muzeum Guggenheima w Bilbao symboliczny charakter budowli rozumieć należy przede wszystkim w kategoriach politycznej relacji pomiędzy Krajem Basków a Hiszpania, interpretując je jako wyraz n i e zal eż nośc i regionu od władzy państwowej. Zarówno w wyborze inwestycji, która miała stać się wizytówką rewitalizacji miasta, jak również w sposobie prowadzenia negocjacji z Fundacją Guggenheima, bardzo wyraźnie przebijają tony polityczne.

Dość znamienny jest fakt, że ani Bilbao, ani żadne inne miasto baskijskie nie uczestniczyło w procesie tworzenia nowego oblicza Hiszpanii w 1992 roku, nazywanym powszechnie ,rokiem Hiszpanii”. To właśnie wtedy w trzech jej znaczących miastach odbywały się niezwykle ważne uroczystości kulturalne i sportowe. Madryt (stolica Hiszpanii) pełnił funkcję Europejskiej Stolicy Kultury, Barcelona (stolica Katalonii) organizowała letnie igrzyska olimpijskie, Sewilla (stolica Andaluzji) zaś - Expo. Muzeum Guggenheima w Bilbao, a więc niezwykle znacząca (i głośna) inwestycja kulturalna, opisywana szeroko w prasie światowej, zupełnie nie wpisywało się w tę narrację tworzenia „nowej Hiszpanii”. Od samego początku było to przedsięwzięcie sensu stricto baskijskie. Jeśli więc łączyć muzeum z 1992 rokiem, to raczej - jak sugeruje Gerardo del Cerro Santamaría - w kategoriach własnej, baskijskiej odpowiedzi na „rok Hiszpanii” (S a n t a m a rí a 2007: 104).

Baskijska wymowa inwestycji miała niebagatelne znaczenie dla społecznego odbioru muzeum. Jeśli nawet początkowo projekt wzbudzał opór i niechęć ze strony lokalnego świata artystycznego (czemu nie do końca trudno się dziwić, biorąc pod uwagę fakt, że na muzeum przeznaczono około $80 \%$ całego budżetu na działalność kulturalna), fakt, że była to inwestycja baskijska, pozwolił na jej stopniowe „oswojenie”, co skutecznie przyczyniło się do tworzenia wokół niej wyraźnie baskijskiej narracji.

Otwarcie Muzeum Guggenheima w Bilbao miało zatem, w pewnym sensie, stanowić namacalny dowód na to, że Baskowie są w stanie uczynić swój kraj częścią globalnego obiegu kulturowego bez pomocy Hiszpanii. Ten polityczny wymiar przedsięwzięcia bardzo dobrze ukazują negocjacje, które odbyły się między Fundacją Guggenheima reprezentowaną przez Thomasa Krensa, a władzami Kraju Basków, w których właściwie nie wykorzystano (z pewnymi znaczącymi wyjątkami) mediacji hiszpańskiej ${ }^{8}$. Joseba Zulaika, w swoim bardzo szczegóło-

${ }^{8}$ Spośród ważnych osób zaangażowanych w proces negocjacji pomiędzy Fundacją Guggenheima a reprezentantami Kraju Basków, które odegrały w nim istotną rolę, a nie były przedstawicie- 
wym opisie przebiegu negocjacji, zwraca uwagę na kilka kluczowych dla całego procesu elementów. Przede wszystkim, jak pisze, Baskowie bardzo dobrze przygotowali się do wizyty Krensa, ,z wyprzedzeniem przestudiowali człowieka i nie pozostawili niczego losowi. Ich główna strategia była jasna: traktować go jak gdyby był głową państwa" (Z u l a i k a 2001: 101). Zgodnie z tym założeniem, na Krensa na bilbaońskim lotnisku czekał więc czerwony dywan, a stamtąd bezpośrednio zabrano go helikopterem, lecąc ponad malowniczym wybrzeżem Mundaki i zielonymi wzgórzami typowymi dla baskijskiego krajobrazu, do Vitorii na spotkanie z Prezydentem Kraju Basków (lehendakari) (t a m ż e: 201-202). Krensowi nie pokazano wówczas bezpośrednio Bilbao (S a nta maría 2007: 107), by nie odwieść go od pomysłu, lecz wybierano te miejsca, które miały znaczenie historyczne i mogły zbudować w nim przekonanie o politycznej niezależności regionu i powadze baskijskiej propozycji. Stąd choćby wizyta w Guernice - miejscu o symbolicznym dla Basków znaczeniu, gdzie pod świętym drzewem władcy Kastylii, a później Hiszpanii, przysięgali, że pozostaną wierni prawom (fueros) Vizcai - jednej z siedmiu historycznych prowincji Kraju Basków, której stolicą jest Bilbao.

Argumentem, który miał ostatecznie przekonać Krensa, była - według Zulaiki - kwestia finansowej samorządności Basków, ucieleśniona we własnym baskijskim systemie podatkowym. Podczas spotkania, do którego doszło pomiędzy Krensem a szwagrem Króla Hiszpanii, mężem Księżnej Sorii, ten ostatni miał zapytać dyrektora Fundacji: „Czy wiesz ile Skarbów Państw jest dziś w Unii Europejskiej? [...] Zapewne pomyślisz, że jest po jednym dla każdego z dwunastu rządów europejskich (jest rok 1991). Otóż nie, jest ich szesnaście. Dwanaście [skarbców] narodów europejskich, plus te, które posiadają prowincje baskijskie: Álava, Vizcaya i Guipúzcoa, a także Nawarra" (Z u l a i k a, 2001: 104-105). To szczególne ekonomiczne uprawnienie dzisiejszych władz Kraju Basków i Nawarry, o którym wspomina powyższy cytat, ma swoje źródła w historii, w tzw. baskijskich fueros, a więc systemie praw i przywilejów, z których prowincje baskijskie korzystały aż do drugiej połowy XIX wieku. Jednym z nich był właśnie własny system podatkowy. Choć w 1876 roku fueros zostały ostatecznie zawieszone, dwa lata później, w 1878 roku wprowadzono w ich miejsce tzw. concierto económico - instrument przywracający Baskom autonomię fiskalną, który z przerwami (okres wojny domowej i dyktatura Generała Franco) obowiązuje do dzisiaj. To on jest podstawowym filarem współczesnej baskijskiej samorządności gospodarczej. Ponieważ prawo do zbierania podatków stanowi jedną z ważniejszych prerogatyw władzy państwowej, wymowa przytoczonej wyżej wypowiedzi była bardzo

lami władz baskijskich, należy wspomnieć przynajmniej o trzech, byli to: Carmen Giménez - dyrektor Hiszpańskiego Narodowego Centrum Wystaw i Alfonso Otazu - baskijski historyk pracujący w hiszpańskim Ministerstwie Kultury, którzy zainicjowali kontakt pomiędzy Baskami i Fundacją, oraz szwagier Króla Hiszpanii, mąż Księżnej Sorii, z którym rozmowa - według przekazu Joseby Zulaiki - miała ostatecznie przekonać Tomasa Krensa do otworzenia muzeum w Bilbao ( $\mathrm{Z}$ u l a i k a 2001: 107-108). 
czytelna. Baskowie nie tylko byli w stanie składać deklaracje dotyczące otwarcia muzeum, lecz w rzeczywistości posiadali wszystkie narzędzia niezbędne do realizacji (i sfinansowania) tego przedsięwzięcia.

Warto w tym miejscu dodać jeszcze jeden znaczący fakt, a mianowicie, że negocjacje ze strony baskijskiej prowadzone były nie przez władze miasta, lecz przez reprezentantów rządu baskijskiego, co dobitnie pokazuje, że projekt od początku ukierunkowany był na zmianę wizerunku regionu, nie tylko miasta. Co więcej, kluczową rolę w całym procesie negocjacyjnym odegrał minister skarbu - nie zaś przedstawiciel departamentu kultury, co jasno wskazuje na intencje strony baskijskiej. Muzeum Guggenheima nie było pomyślane jako inwestycja kulturowa (w gestii Fundacji pozostawiono np. kompetencje w zakresie decydowania o ekspozycji), lecz miało być flagowa, ikoniczną budowlą mogącą odmienić sposób postrzegania regionu w świecie.

\section{Bilbao Ria 2000. Wartości ekonomiczne w praktyce}

Kluczową rolę w procesie rewitalizacji miasta odgrywała Bilbao Ria 2000 (BR2000), formalnie prywatna organizacja non-profit, założona w 1992 roku, której głównym celem była (i jest) realizacja działań rewitalizacyjnych na zdegradowanych obszarach miasta i jego terenach poprzemysłowych. Udziałowcami BR2000 są wyłącznie instytucje publiczne, przy zachowaniu zasady równego podziału praw własności między administracje centralną i regionalną. Tę pierwszą (hiszpańską) reprezentują takie podmioty, jak: SEPES (Entidad Publica Empresarial de Suelo, Publiczne Przedsiębiorstwo Lądowe zajmujące się zagospodarowaniem terenu publicznego) - 25\% własności, a także hiszpańskie władze portowe $-10 \%$ i kolejowe $-15 \%$. Drugą zaś (baskijską) reprezentuje: rząd baskijski (Govierno Vasco) - 15\%, deputacja foralna Vizcai (Diputacion Foral de Bizkaia) - 15\%, władze miasta Bilbao (Ayuntamientos de Bilbao) - 15\% oraz władze miejskie Baracaldo (Ayuntamiento de Barakaldo) - 5\%.

Bilbao Ria 2000 powstała przede wszystkim jako organizacja zarządzająca procesami rewitalizacji miasta, które w "Generalnym planie zagospodarowania przestrzeni miejskiej Bilbao” (PGOU) z końca lat 80. uznano za tzw. „obszary możliwości”. Najbardziej znaczącą z nich, z punktu widzenia przemian wizerunku Bilbao, była Abandoibarra, centralnie położona nadrzeczna część miasta, gdzie usytuowane zostało Muzeum Guggenheima, a która jako całość stanowiła flagową inwestycję bilbaońskiego procesu rewitalizacyjnego. Ponieważ prowadzenie działań na terenach znajdujących się w rękach różnych podmiotów stanowi duże wyzwanie, a tak było w przypadku Abandoibarry, która co prawda w aż 95\% znajdowała się w rękach publicznych, to jednak prawa własności gruntów podzielone były między rożne instytucje, w tym hiszpańskie koleje: RENFE, Narodowy Instytut Przemysłu (Instituto Nacional de Industria, INI), władze portowe oraz władze miejskie, BR2000 miała - w zamyśle - usprawnić prowadzenie działań rewitalizacyjnych, tj. koordynować działania i rozstrzygać kwestie problemowe. 
Istnieją dwa zasadnicze powody, które mogą thumaczyć sukces strategii zarządzania procesem rewitalizacji przez BR2000. Pierwszy z nich kryje się w sposobie finansowania. Bilbao Ria 2000 rozpoczęła swoją działalność z kapitałem początkowym w wysokości 1,8 mln EUR, który został wniesiony przez jej udziałowców. Była to jedyna tego typu kontrybucja. Od tego czasu BR2000 funkcjonuje na zasadzie samofinansowania zgodnie z następującą zasadą: udziałowcy BR2000 (a więc podmioty publiczne) przekazują $\mathrm{w}$ jej zarząd posiadane przez siebie grunty, jeśli te znajdują się na zdegradowanym, a mającym podlegać procesowi rewitalizacji obszarze. Teren ten następnie zostaje przekształcony zgodnie z przyjętymi planami rewitalizacji, cześś działek o istotnym znaczeniu (mają na nich powstać obiekty użyteczności publicznej lub tereny zielone) pozostaje w rękach publicznych, reszta z kolei zostaje odsprzedana w ręce prywatne. Wypracowane w ten sposób zyski ze sprzedaży (wartość gruntu na obszarach w procesie regeneracji ulega znacznemu podwyższeniu) zostają dalej zainwestowane do realizacji kolejnych projektów rewitalizacyjnych (Urban Redevelopment Authority 2012: 32). W rezultacie, BR2000 nie sięga po środki publiczne, stara się natomiast korzystać z dotacji unijnych.

Idea samofinansowania, jako instrument konieczny dla zapewnienia skuteczności realizacji działań rewitalizacyjnych, nie jest - na gruncie baskijskim - niczym nowym. W dużej mierze jest ona wpisana w przedstawiony powyżej system autonomii fiskalnej Kraju Basków, reprezentowany współcześnie przez concierto económico. Ponieważ Baskowie sami ściagają swoje podatki i z nich finansują przeważającą większość prowadzonych przez siebie działań - w odróżnieniu od innych regionów Hiszpanii - nie są ani przyzwyczajeni, ani uzależnieni od transferów z budżetu centralnego (por. Gra y 2015). Sprzyja to większej dyscyplinie finansowej, a to z kolei może thumaczyć, dlaczego Kraj Basków jest obszarem, który wyraźnie lepiej niż wiele pozostałych ziem Hiszpanii zniósł ostatni kryzys finansowy.

Drugim powodem sukcesu bilbaońskiej polityki rewitalizacyjnej jest jej zakorzenienie w baskijskich wartościach wspólnotowych. Każdy, kto miał okazję dłużej przebywać w Kraju Basków, musiał zwrócić uwagę na dwie fundamentalne wartości, na których opiera się tamtejszy system społeczny. Pierwszą z nich jest mający kluczowe znaczenie dla organizacji życia społecznego: baskijski e g a li t a ry z m, wpisany w historię Basków i symbolicznie wyrażony przez baskijski beret (boina). Drugim z kolei jest zas ada k omunitary zmu, a więc wspólnoty działania, a w konsekwencji także postrzegania wartości wspólnych jako ważnych dla wszystkich jej członków. Funkcjonowanie baskijskiego komunitaryzmu polega na tym, że idea dobra wspólnego nie jest przez Basków przeciwstawiana interesom jednostkowym, jak to często ma miejsce, lecz postrzegana jako z nimi kompatybilna. Wartości indywidualne w pewnym więc sensie zawierają się i wyrażają w baskijskich wartościach wspólnych.

Spośród wielu przykładów mogących ilustrować sposób funkcjonowania tych wartości, koniecznie przytoczyć trzeba dwa. Pierwszy ma charakter historyczny i odwołuje się do organizacji życia społecznego w okresie preindustrialnym. Drugi z kolei odnosi się do współczesnych form organizacji aktywności gospodarczej. 
Ziemie baskijskie, w szczególności te w regionie obecnego bilbaońskiego obszaru metropolitarnego, od wieków słynęły ze swojej zasobności w żelazo, które było niezwykle cenionym baskijskim towarem eksportowym. Choć duża eksploatacja kopalń mogła zapewnić potencjalnym jej właścicielom wysokie zyski, zgodnie z obowiązującym na ziemiach baskijskich prawem, kopalnie przez stulecia uznawane były za własność municypalną, co znaczy, że każdy kto mieszkał na tych terenach (a więc w praktyce był Baskiem), mógł korzystać $\mathrm{z}$ ich zasobów. Takie rozwiązanie - choć zdawałoby się niezbyt optymalne z punktu widzenia czystego rachunku ekonomicznego - było zarazem gwarantem ładu społecznego, zapewniającym równościowy charakter stosunków na wsi baskijskiej, a równocześnie wzmacniającym współpracę sąsiedzką przy wydobywaniu zawartych w kopalni bogactw naturalnych. Dopiero za sprawą działań hiszpańskiej władzy państwowej i prowadzonej w XIX wieku polityki „dezamortyzacji” tereny te, jako typowy przykład „dóbr martwej ręki”, zostały wywłaszczone, a następnie odsprzedane w ręce prywatne (por. Or ze c h ow s k a-Wa c ław s k a 2014b).

Drugi, współczesny przykład funkcjonowania baskijskich wartości ekonomicznych odnosi się do sfery gospodarczej i reprezentowany jest przez popularny w Kraju Basków system kooperatyw. W samej już idei kooperatywizmu zawieraja się obydwie wartości: komunitaryzmu - tj. wspólnej pracy na rzecz osiagania wspólnych celów, i egalitaryzmu - co wyraża się w prawie głosu przysługującemu każdemu z członków kooperatywy, jak również (często, choć nie zawsze) w spłaszczonych widełkach płacowych (tak było np. na poczattku powstania kooperatyw mondragońskich, gdy początkowo przedział płac zamykał się w proporcji 1:3).

W opisywanej tu Bilbao Ria 2000, wartości te wyrażają się, jeśli nie w całkowitym braku, to przynajmniej w nieznacznej i dającej się pogodzić rozbieżności pomiędzy interesami konkretnych udziałowców a tym, co rozumie się pod pojęciem interesu publicznego. Świetną ilustracją łączenia interesu własnego z publicznym jest stosowana przez udziałowców BR2000 zasada kontrybucji ich gruntów (co przecież w innych warunkach samo w sobie stanowiłoby podstawowy problem) na rzecz realizacji inwestycji mających służyć wspólnemu celowi, jakim jest poprawa kondycji miasta i jakości życia jego mieszkańców.

\section{Baskijski Guggenheim, czyli kilka uwag o spójności narracji. Podsumowanie}

Zrozumienie istoty bilbaońskiej rewitalizacji i roli, jaką odgrywa obecnie w przestrzeni baskijskiej Muzeum Guggenheima, wymaga odwołania się do sposobu funkcjonowania Basków we współczesnym świecie i ich wizji samych siebie. Jak wspomniałam, otwarcie Muzeum Guggenheima w Bilbao było swego rodzaju deklaracją polityczną. Baskowie zaznaczali w ten sposób swoją obecność w świecie globalnym, omijając przy tym poziom państwa narodowego (hiszpań- 
skiego). W takim znaczeniu muzeum interpretować można jako swego rodzaju strategię na „zaistnienie” miasta i szerzej regionu we współczesnym usieciowionym świecie. To jak skutecznie efekt ten udało się osiagnąć i jak dalece bilbaońskie Muzeum Guggenheima funkcjonuje dziś w różnych wymiarach sieciowych, świetnie opisują Beatrize Plaza i Silke Haarich (P l a z a, H a a r i c h 2013).

$\mathrm{W}$ tej strategii wychodzenia naprzeciw wyzwaniom globalizacji nie ma nic nadzwyczajnego - cały proces internacjonalizacji gospodarki baskijskiej prowadzony systematycznie od lat 80./90. XX wieku ukierunkowany był właśnie na budowanie przez firmy baskijskie silnych relacji ekonomicznych w świecie (nie tylko w Hiszpanii), a bardzo dobrym tego przykładem jest proces rozwoju kooperatyw mondragońskich, które zamieniły się w prawdziwą korporację międzynarodową.

Co znaczące, punktem odniesienia dla tworzenia strategii rozwoju Kraju Basków nie są dziś inne regiony Hiszpanii, czy Hiszpania jako taka, lecz inne regiony europejskie i miasta światowe. Stąd choćby inicjatywa, która pojawiła się swego czasu, by przemienić Kraj Basków w najbardziej innowacyjny region Europy. Determinacja i skala, z jaką proces ten był (i jest) realizowany, jest w istocie niezwykła i zdaje się przynosić bardzo dobre rezultaty. Bilbao, niegdyś miasto industrialne, przemieniając całkowicie swoje oblicze, zamieniło się dziś w rozpoznawany na świecie ośrodek designu, zbierając rożne nagrody i wyróżnienia, w tym m.in. prestiżową Nagrodą Lee Kuan Yew World City w 2010 roku.

Muzuem Guggenheima, w kontekście tej niezwykłej transformacji zarówno społecznej, jak i przestrzennej, rozumieć trzeba zarówno jako szczególny jej przejaw, a więc świadectwo nowoczesności i innowacyjności regionu i społeczności, jak też i motor dalszych zmian. Wbrew niektórym opiniom, że muzeum nie odwołuje się do lokalnego świata baskijskiego i nie angażuje lokalnej kultury (por. Mi c h a e 12015), sądzę, że Muzeum Guggenheima bardzo dobrze wkomponowało się zarówno w lokalną panoramę - zgadzam się tu z opinią Małgorzaty Dymnickiej, że „,muzeum wkracza w życie miasta, jego społeczne przestrzenie” (D y m n i c k a 2013: 182), jak i w życie społeczno-artystyczne (P l a z a , H a a r i c h 2013). Muzueum Guggenheima - tak jak sama jego budowla, z jednej strony odwołująca się do industrialnej surowej historii miasta, $\mathrm{z}$ drugiej zaś przełamująca schematy i standardy sztuki architektonicznej - ewokuje nowoczesnością i zaczyna dziś funkcjonować także w odbiorze samych bilbaończyków jako ważny symboliczny punkt odniesienia dla budowy otwartej na świat, lecz równocześnie głęboko zakorzenionej w wartościach wspólnotowych współczesnej baskijskości.

\section{Bibliografia}

A shworth G., Kavaratzis M. (2014), Cities of Culture and Culture in Cities: The Emergent Uses of Culture in City Branding, [w:] H a s T., Ols s on K. (eds.), Emergent Urbanism: Urban Planning \& Design in Times of Systemic and Structural Change, Ashgate, Aldershot. 
Clark G., Hux le y J., M o unt ford D. (2010), Organising Local Economic Development. The Role of Development Agencies and Companies, OECD.

Dy m n c k a M. (2013), Przestrzeń publiczna a przemiany miasta, Scholar, Warszawa.

G ib s o n L., S t e v e n s o n D. (2004), Urban Space and the Uses of Culture, „International Journal of Cultural Policy", no. 10, s. 1-4.

Góme z M., Go nzále z S. (2001), A Reply to Beatriz Plaza's 'The Guggenheim-Bilbao Museum Effect', "International Journal of Urban and Regional Research", vol. 25, no. 4, s. 898-900.

Gray C. (2015), A Fiscal Path to Sovereignty? The Basque Economic Agreement and Nationalist Politics, "Nationalism and Ethnic Politics", vol. 21, no. 1, s. 63-82.

Hug hes R. (1997), Bravo! Bravo! R. Meier's Getty Center and F. Gehry's Guggenheim Museum, "Time", no. 150.

Kavaratzis M., A shworth G. (2015), Hijacking Culture: The Disconnection Between Place Culture and Place Brands, "The Town Planning Review", vol. 86, no. 2, s. 155-176.

J o h n s o n L. (2009), Cultural Capitals. Revaluing the Arts, Remaking Urban Spaces, Ashgate Publishing Co., Farnham.

M a c Clan c y J. (2007), Expressing Identities in the Basque Arena, Long House Publishing Services, Oxford-Santa Fe.

Mc Ew an C. (2005), Geography, Culture and Global Change, [w:] D a n i e ls P. et al. (eds.), An Introduction to Human Geography: Issues for the 21st Century, Pearson, Harlow.

Michael Ch. (2015), The Bilbao Effect: Is 'starchitecture' all it's cracked up to be? A history of cities in 50 buildings, day 27, "The Guardian", 30.04. [online].

Mu s ch a m p H. (1997), The Miracle in Bilbao, "New York Times Magazine", no. 146.

Orzechowska-Wacławska J. (2014a), Baskijskie polityki miejskie. Konstruowanie nowej symboliki i nowego oblicza Bilbao, „Politeja”, nr 27, s. 209-227.

Orzechowska-Wacławska J. (2014b), Baskowie. Powstawanie współczesnego narodu, Wydawnictwo Uniwersytetu Jagiellońskiego, Kraków.

P la z a B. (2008), On Some Challenges and Conditions for the Guggenheim Museum Bilbao to be an Effective Economic Re-activator, "International Journal of Urban and Regional Research", vol. 32 , no. 2 , s. 506-517.

Plaza B. (2006), The Return on Investment of the Guggenheim Museum Bilbao, "International Journal of Urban and Regional Research", vol. 20, no. 2, s. 452-467.

Pl a za B., H a a r c h S. N. (2015), The Guggenheim Museum Bilbao: Between Regional Embeddedness and Global Networking, "European Planning Studies", vol. 23, no. 8, s. 1-20.

S ant a maría G. del Cerro (2007), Bilbao. Basque Pathways to Globalization, Elsevier, Amsterdam.

S c o t t A. J. (2014), Beyond the Creative City: Cognitive - Cultural Capitalism and the New Urbanism, "Regional Studies", vol. 48, no. 4, s. 565-578.

S elig mann A. D. (2008), Architectural Publicity in the Age of Globalization, PhD Dissertation, University of California, Los Angeles.

Serra E. M. (2011), La revitalización del área metropolitana de Bilbao: La gestión del Bilbao Ría 2000, aspectos territoriales, "Boletín de la Asociación de Geógrafos Españoles", no. 55, s. 35-57.

S w i d l e r A. (1986), Culture in Action: Symbols and Strategies, "American Sociological Review", no. 51 , s. 273-286.

Urban Redevelopment Authority (2012), Cities in Transformation: Lee Kuan Yew World City Prize, Tien Wah Press, Singapore.

Vicario L., Martín ez Monje P. M. (2003), Another 'Guggenheim Effect'? The Generation of a Potentially Gentrifiable Neighbourhood in Bilbao, "Urban Studies", vol. 40, no. 12, s. $2383-2400$. 
$\mathrm{Z}$ abaleta I. (1999), The Basques in the International Press: Coverage by the New York Times (1950-1996), [w:] D o u g l a s W. A. et al. (eds.), Basque Politics and Nationalism on the Eve of the Millennium, University Nevada Press, Reno.

Zu l a i k a J. (2001), Krens's Taj Mahal: The Guggenheim's Global Love Museum, "Discourse", vol. 23 , no. 1 , s. $100-118$.

Joanna Orzechowska-Waclawska

\title{
THE BASQUE APPROACH TO URBAN REGENERATION. THE CULTURAL CODE OF "THE GUGGENHEIM EFFECT"
}

\begin{abstract}
In this article I analyze the so-called: "Bilbao effect". I am interested primarily in the relationship between the revitalization of Bilbao with its iconic building - the Guggenheim Museum and the Basque culture, i.e. the Basque way of life and the Basque values. The starting point of this analysis is the concept of "urban regeneration through culture", which is usually understood in one of two ways. The first meaning refers to such activities that rely on the use of cultural institutions in the urban regeneration projects, whereas the second refers to the activities that engage and activate (local) artists. Both interpretations tend, however, to distort the meaning of culture. In both cases it is understood very narrowly and operates merely as the synonym of "the arts".

Basing on Znaniecki's definition, who understood culture, not only in material terms but also as everything that falls within the category of so-called "intangible creations of human activity", I analyze the "cultural dimension" of urban regeneration of Bilbao not through the typical presentation of Guggenheim Museum as a cultural institution, but rather through the choice of revitalization strategies and its socio-cultural basis. In doing so, I explore the connections between the Guggenheim Museum in Bilbao and the Basque political philosophy, Basque economic values, and the Basques image of themselves.
\end{abstract}

Key words: Guggenheim Museum, Bilbao, revitalization, urban regeneration, Basque Country 